\title{
Release of Cationic Drugs from Charcoal
}

\author{
Chiara Di Ruocco, Maria Rosaria Acocella and Gaetano Guerra * \\ Department of Chemistry and Biology and INSTM Research Unit, Università di Salerno, via Ponte don Melillo, \\ 84084 Fisciano (SA), Italy; c.diruocco1@studenti.unisa.it (C.D.R.); rosyaco@hotmail.it (M.R.A.) \\ * Correspondence: gguerra@unisa.it; Fax: +39-089-969603
}

Received: 1 February 2019; Accepted: 21 February 2019; Published: 25 February 2019

\begin{abstract}
The goal of this research is to improve preparation of charcoal adducts in a manner suitable for cationic drug release, possibly using an eco-friendly procedure. Charcoal, widely commercialized for human ingestion, is oxidized by hydrogen peroxide in mild conditions. Adducts of a cationic drug (lidocaine hydrochloride, a medication used as local anesthetic) with charcoal are prepared after basification of charcoal and characterized mainly by elemental analysis, wide-angle X-ray diffraction, infrared spectroscopy and thermogravimetry. The drug in the prepared adducts is present in amount close to $30 \%$ by weight and can be readily released to both neutral and acidic aqueous solutions. Cation release, as studied by UV spectra of aqueous solutions, is faster in acidic solutions and is faster than for adducts with graphite oxide, which can be prepared only in harsh conditions.
\end{abstract}

Keywords: wide angle X-ray diffraction; infrared spectra; $\mathrm{pH}$ sensitive ion release

\section{Introduction}

Cationic amphiphilic drugs and antibacterials constitute one of the largest classes of pharmaceutical compounds [1-10].

Different systems for controlled release of cationic drugs are used. Cationic drugs may be bound to anionic polymeric exchange resins (i.e., to a polyelectrolyte), which are generally used after incorporation into liquids or tablets [11]. Sensitive cationic drugs can also be included in delivery systems based on $\mathrm{pH}$-responsive nanogels, to improve their stabilization and control their release [12].

The release of antibacterial cations from intercalation and exfoliation compounds of layered structures, like clays [13-18] and graphite oxide (GO) [19-23] has also been suggested. The application of clays as carrier of antibacterial quaternary ammonium or phosphonium salts is limited by their bad dispersion in water [17,18]. Applications of graphite oxide [19-23] or of oxidized carbon black [24] as cationic drug carriers is possibly limited by the harsh oxidations procedures needed for preparation of intercalation or exfoliation compounds [19-24].

In this paper, we describe an eco-friendly procedure leading to adducts of cationic drugs with charcoal, which are possibly suitable for cationic drug release. In this respect, it is worth noting that charcoal is widely used to treat human flatulence, indigestion and diarrhea, without professional prescription.

In particular, we describe oxidation of charcoal by hydrogen peroxide in mild conditions and preparation of compounds of oxidized charcoal with lidocaine hydrochloride, which is a medication used as local anesthetic [25,26]. Release of lidocaine, from polymer gels [27-31] as well as from liquid crystal structures [32] and polymer threads [33], has been widely studied in the literature. Presently, release of this cationic drug in neutral and acid aqueous solutions from adducts with GO and oxidized charcoal are compared. 


\section{Experimental}

\subsection{Materials, Oxidation Procedures and Preparation of Compounds}

Charcoal (Carbo lignis pulveratus) was from Caesar \& Loretz GmbH (Hilden, Germany). Its Oxygen/Carbon weight ratio, as evaluated by elemental analysis, was high $(\mathrm{O} / \mathrm{C}=0.29)$. Lidocaine hydrochloride monohydrate was supplied by Sigma-Aldrich (Milano, Italy).

Oxidation of charcoal was conducted by hydrogen peroxide at $60{ }^{\circ} \mathrm{C}$. In a typical procedure, $1 \mathrm{~mL}$ of $\mathrm{H}_{2} \mathrm{O}_{2} 30 \mathrm{wt}$.\% was used for $2 \mathrm{mg}$ of charcoal. The $\mathrm{O} / \mathrm{C}$ ratio progressively increased with the treatment time, reaching 0.7 after $24 \mathrm{~h}$. Most of the reported results refer to charcoal oxidized for $24 \mathrm{~h}$. A similar oxidation procedure has been used to achieve edge oxidation of graphite platelets [34].

GO samples were prepared by Hummers' method [35] from high surface area graphite [36] (Synthetic Graphite $8427^{\circledR}$, from Asbury Graphite Mills Inc. (Asbury, NJ, USA), with a minimum carbon wt.\% of 99.8 and a surface area of $330 \mathrm{~m}^{2} / \mathrm{g}$.

Both oxidized charcoal and GO were basified before preparation of their compounds with the cationic drug. In particular, powders $(100 \mathrm{mg})$ were dispersed in $0.05 \mathrm{M} \mathrm{NaOH}$ solution $(20 \mathrm{~mL})$ and stirred for 15 minutes. Lidocaine aqueous solution (100 mL) was added in this dispersion and the reaction mixture was stirred at room temperature for 1 . The reported results refer to the charcoal/lidocaine with a weight ratio of $1 / 3$. Similar results were obtained by operating in excess of lidocaine. The slurry was washed with deionized water and dried at $60{ }^{\circ} \mathrm{C}$ for $12 \mathrm{~h}$.

\subsection{Characterization Methods}

Elemental analyses were performed with a Thermo FlashEA 1112 Series CHNS-O analyzer by Thermo Fisher Scientific Inc. (Waltham, MA, USA), after pretreating samples in an oven at $100{ }^{\circ} \mathrm{C}$ for $12 \mathrm{~h}$.

Surface areas of the used carbon materials were measured by nitrogen adsorption at liquid nitrogen temperature $(77 \mathrm{~K})$ with a Nova Quantachrome 4200e instrument by Quantachrome Instruments (Boynton Beach, FL, USA). Before adsorption measurements, samples were degassed at $60{ }^{\circ} \mathrm{C}$ under vacuum for $24 \mathrm{~h}$. The surface area $\left(\mathrm{SA}_{\mathrm{BET}}\right)$ values were determined by using 11-point Brunauer-Emmett-Teller (BET) analysis.

Thermogravimetric analyses (TGA) were carried out on a TG 209 F1, manufactured by Netzsch Geraetebau $\mathrm{GmbH}$ (Selb, Germany), from 20 to $800^{\circ} \mathrm{C}$ at a heating rate of $10{ }^{\circ} \mathrm{C}$, under $\mathrm{N}_{2}$ flow.

Wide-angle X-ray diffraction (WAXD) patterns were obtained in reflection, at $35 \mathrm{kV}$ and $40 \mathrm{~mA}$, using the nickel filtered $\mathrm{Cu}-\mathrm{K} \alpha$ radiation (1.5418 $\AA$ ), by an automatic Bruker D8 Advance diffractometer (Karlsruhe, Germany).

FTIR spectra were obtained at a resolution of $2.0 \mathrm{~cm}^{-1}$ with a FTIR spectrometer (Bruker Vertex70, Bruker, Karlsruhe, Germany) equipped with deuterated triglycine sulfate (DTGS) detector and a $\mathrm{KBr}$ beam splitter, using $\mathrm{KBr}$ pellets. The frequency scale was internally calibrated to $0.01 \mathrm{~cm}^{-1} \mathrm{using}$ a He-Ne laser. 32 scans were signal averaged to reduce the noise.

UV-vis spectra were recorded using a Perkin Elmer Lambda 800 UV-vis spectrophotometer (Waltham, MA, USA).

The released amount of lidocaine from adducts with charcoal and GO, in neutral (1 wt.\% of $\mathrm{NaCl})$ and acid $(0.05 \mathrm{M}$ of $\mathrm{HCl})$ aqueous solutions was measured as a function of the soaking time. A sealed cellulose filter ("Macherey-Nagel MN226", Düren, Germany), containing 50 mg of powder compounds, was soaked in a flask with $0.1 \mathrm{~L}$ of aqueous solution at room temperature, maintaining the system constantly stirred. Aliquots of the transparent aqueous solution were sampled by syringe after different times and the concentrations of the released lidocaine were measured by using an UV-vis spectrophotometer. 


\section{Results and Discussion}

\subsection{Oxidation of Charcoal by Hydrogen Peroxide}

The used charcoal has the composition shown in Table 1, as determined by elemental analysis. The observed $\mathrm{O} / \mathrm{C}$ weight ratio was definitely higher than for carbon black samples, being generally lower than 0.1 . Its surface area was rather low: $\mathrm{SA}_{\mathrm{BET}} \approx 50 \mathrm{~m}^{2} / \mathrm{g}$.

Table 1. Elemental analysis of charcoal after different times of oxidation by $\mathrm{H}_{2} \mathrm{O}_{2}$. The last column indicates the water content as determined by thermogravimetry.

\begin{tabular}{ccccccc}
\hline Charcoal & \%N & \%C & $\% \mathbf{H}$ & $\% \mathbf{O}$ & $\mathbf{O} / \mathbf{C}$ & \% $_{\mathbf{2}} \mathbf{O}$ \\
\hline Untreated & 0.3 & 74.8 & 4.2 & 20.7 & 0.29 & 4.0 \\
$\mathrm{H}_{2} \mathrm{O}_{2}$ oxidized, 3 h & 1.0 & 68.8 & 1.9 & 28.2 & 0.41 & 5.6 \\
$\mathrm{H}_{2} \mathrm{O}_{2}$ oxidized, 6 h & 1.0 & 67.4 & 1.8 & 29.8 & 0.44 & 6.1 \\
$\mathrm{H}_{2} \mathrm{O}_{2}$ oxidized, 24 h & 0.9 & 57.2 & 1.5 & 40.4 & 0.70 & 7.6 \\
\hline
\end{tabular}

The X-ray diffraction pattern of charcoal (upper curve of Figure 1) showed two very broad amorphous halos, broader than those observed for carbon black samples (the pattern of a carbon black with a surface area of $150 \mathrm{~m}^{2} / \mathrm{g}$ is shown, for comparison, as the lower curve in Figure 1) [24]. Diffraction halos of carbon black were interpreted by a disordered spatial arrangement of defective graphene layers, exhibiting short in-plane correlation length (typically in the range of 2-3 nm), as confirmed by the ability of oxidized carbon black (oCB) to form ordered intercalation compounds, with ammonium cations [24]. The broader amorphous halos of charcoal clearly indicated the occurrence of a higher degree of disorder associated with its high oxygen content.

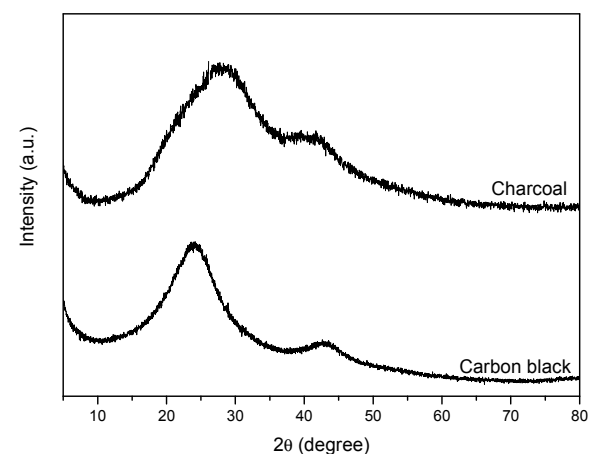

Figure 1. Wide-angle X-ray diffraction (WAXD) patterns of the used charcoal and of a typical carbon black sample.

Irrespective of its high oxygen content, the used charcoal after basification was only able to bind small amounts of cations; e.g., the content of bound cationic lidocaine is lower than 2 wt.\%. Hence, to get compounds with significant cation content, higher degrees of oxidation were needed. However, due to the low degree of structural order, mild oxidation conditions were sufficient to get degrees of oxidation suitable for adduct formation with cations. In particular, oxidation at $60{ }^{\circ} \mathrm{C}$ by hydrogen peroxide (30 wt.\%) is sufficient to achieve $\mathrm{O} / \mathrm{C}$ weight ratios as high as 0.7 (Table 1 ), analogous to those obtained with high-surface-area graphite by the harsh Hummers' method. It is also worth adding that for oxidation of carbon black by Hummers' method, $\mathrm{O} / \mathrm{C}$ weight ratios higher than 0.6 are only reached for carbon black samples with a surface area higher than $120 \mathrm{~m}^{2} / \mathrm{g}$ [24]. Hence the substantial oxidation of charcoal already by hydrogen peroxide was not due to its surface area (definitely low, $\mathrm{SA}_{\mathrm{BET}} \approx 50 \mathrm{~m}^{2} / \mathrm{g}$ ) but rather to its defective structure associated with its high starting oxygen content.

The charcoal oxidation was clearly apparent by FTIR spectra, like those of Figure 2A. As a consequence of oxidation, an absorbance peak at $1720 \mathrm{~cm}^{-1}$ appears that becomes very intense after $24 \mathrm{~h}$ of treatments, 
clearly indicating the formation of carboxylic groups. An increase of intensity of the band in the range $1270-1120 \mathrm{~cm}^{-1}$ was also observed, with two peaks centered at $1155 \mathrm{~cm}^{-1}$ and $1215 \mathrm{~cm}^{-1}$, which are possibly due to phenol C-O groups [37,38].
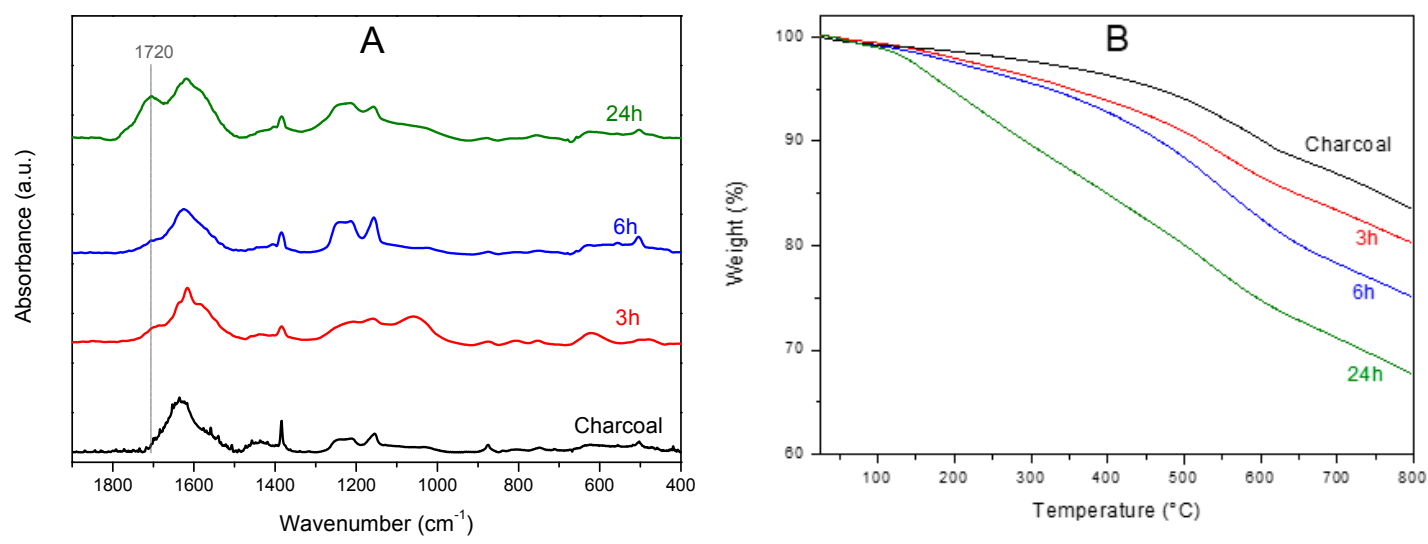

Figure 2. (A) FTIR spectra and (B) TGA scans of the used charcoal sample after different times of oxidation by $\mathrm{H}_{2} \mathrm{O}_{2}$ at $60^{\circ} \mathrm{C}$.

The charcoal oxidation was also associated with large changes in the thermogravimetric behavior, as clearly apparent by TGA scans shown in Figure 2B. In fact, as the O/C ratio increased the degradation phenomena were shifted toward lower temperatures.

\subsection{Formation of Adducts between Oxidized Charcoal and Organic Cations}

For oxidized $\mathrm{CB}$, adduct formation procedures with tetraalkylammonium cations exhibiting two long hydrocarbon tails (2HT) lead to intercalated compounds [24]. This was clearly shown by the appearance, for samples with $\mathrm{O} / \mathrm{C}>0.5$, of well-defined diffraction peaks that can be rationalized as 001,003 and 005 reflections of an oCB /2HT intercalate structure, with a periodicity of $d=4.8 \mathrm{~nm}$ (Figure 6 in Reference [24]).

The same procedure, when applied to oxidized charcoal, also leads to formation of adducts, as proved by the occurrence of cation exchange and weight increase. However, no crystalline peaks appeared indicating that no intercalate structure was formed. This clearly confirms the presence in charcoal of a definitely higher degree of disorder, relative to $\mathrm{CB}$, as suggested by the diffraction halos of Figure 1.

Neither oCB or oxidized charcoal were able to form intercalate adducts with lidocaine and in both cases only disordered adducts were obtained.

A TGA scan of the lidocaine adduct with oxidized charcoal $(\mathrm{O} / \mathrm{C}, \mathrm{wt} / \mathrm{wt}=0.7)$, as prepared in the presence of a large excess of the organic salt (C/lidocaine weight ratio of $1 / 3)$, is shown in Figure 3A. A comparison with TGA of the starting basified charcoal (upper scan in Figure 3A) and of lidocaine hydrochloride (lower scan in Figure 3A) shows that the obtained adduct presented a lidocaine content close to $30 \mathrm{wt} . \%$.

The X-ray diffraction pattern of this adduct is shown in Figure 3B and presents only the broad diffraction halo of charcoal. A comparison with the WAXD spectrum of lidocaine hydrochloride (bottom patterns in Figure 3B) clearly shows that the crystallinity of lidocaine hydrochloride was completely lost as a consequence of adduct formation. A similar behavior was observed for adducts of lidocaine hydrochloride with GO. 

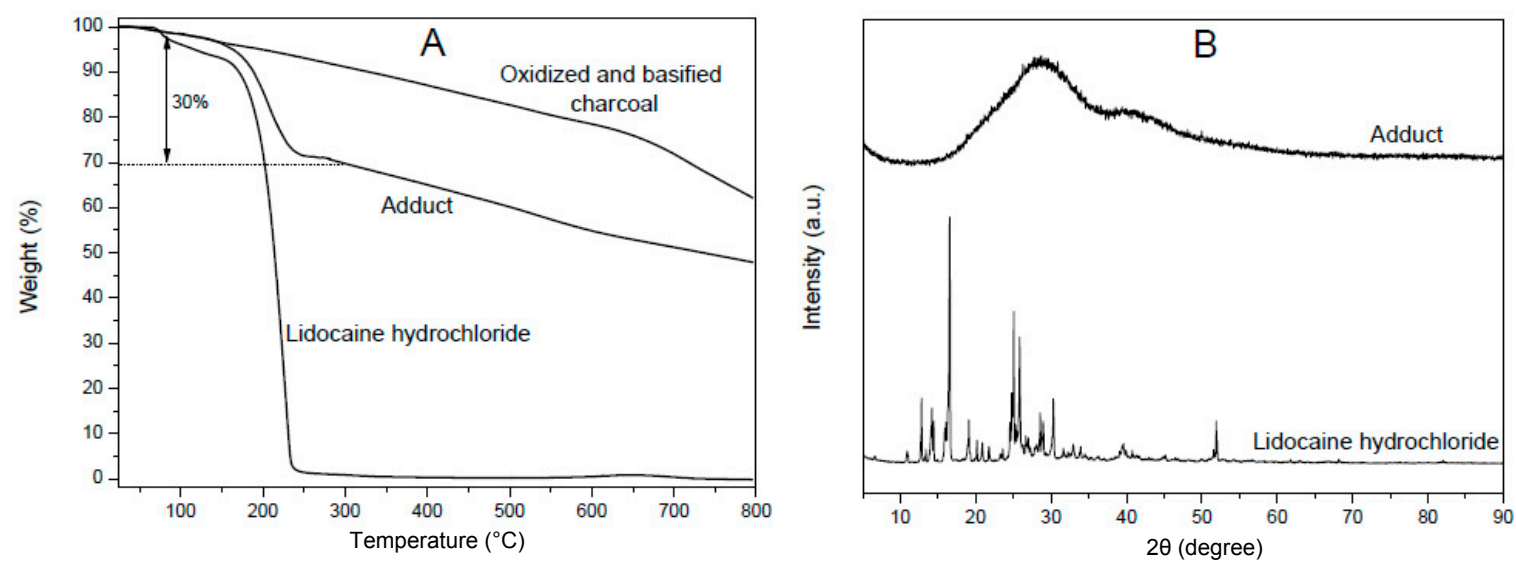

Figure 3. TGA scans (A) and WAXD patterns (B) of lidocaine hydrochloride and of its adducts with oxidized and basified charcoal (charcoal/lidocaine, 70/30 wt/wt), as prepared by a large excess of lidocaine.

\subsection{Lidocaine Release from Adducts with Oxidized Charcoal and Graphite Oxide}

The obtained adducts of lidocaine with oxidized charcoal and graphite oxide presented similar large lidocaine content (30 wt. $\%$ and $33 \mathrm{wt} . \%$, respectively). These adducts were compared for their kinetics of release of the ionic drug in aqueous solutions, neutral $(\mathrm{pH}=7$ with $1 \mathrm{wt} . \%$ of $\mathrm{NaCl})$ and acid $(\mathrm{pH}=1.3, \mathrm{HCl} 0.05 \mathrm{M})$, roughly corresponding to the $\mathrm{pH}$ of a human colon and stomach, respectively. The released amounts were evaluated by UV measurements in the spectral range 240-300 nm on the solutions, as shown for adducts with oxidized charcoal in Figure 4.
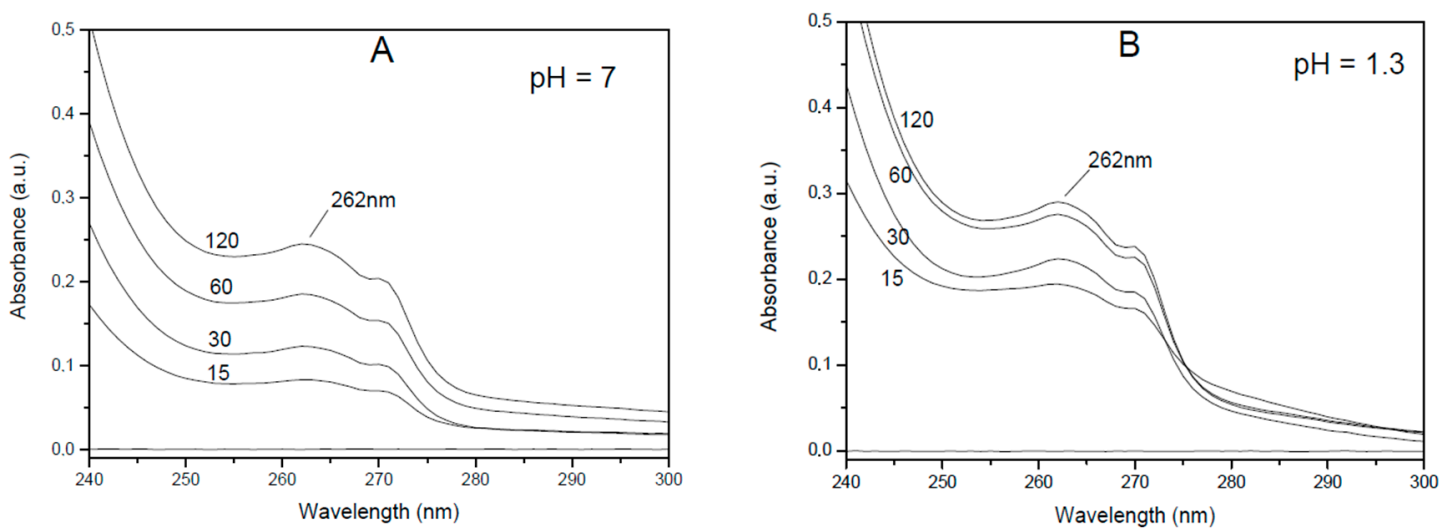

Figure 4. UV spectra in the $240-300 \mathrm{~nm}$ range of aqueous solutions, after different soaking times (from $15 \mathrm{~min}$ up to $120 \mathrm{~min}$ ) of the lidocaine adduct with oxidized charcoal: (A) neutral saline solution; (B) acidic $(\mathrm{pH}=1.3)$ solution.

The released amount of lidocaine from adducts with charcoal (red continuous curves) and GO (black dashed curves), in neutral and acidic $(\mathrm{pH}=1.3$ ) aqueous solutions are reported versus the soaking time in Figure 5.

The data of Figure 5 show that the release of the ionic drug in the aqueous acid solution was complete, for adducts with oxidized charcoal and oxidized graphite, after $1 \mathrm{~h}$ and $2 \mathrm{~h}$, respectively. For both neutral and acidic solutions, the cation release was faster for the charcoal adduct than for the GO adduct. 


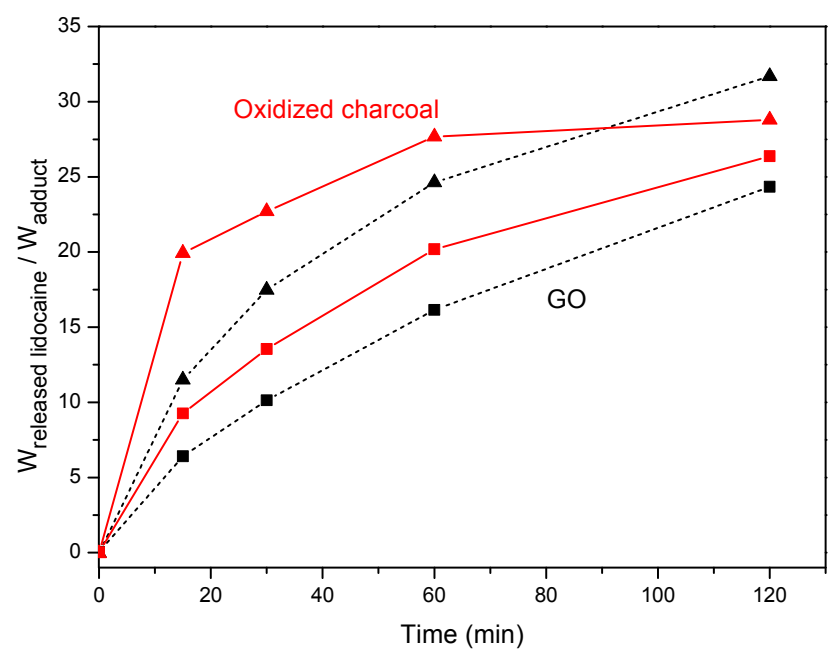

Figure 5. Lidocaine release from its adducts with oxidized charcoal (red continuous curves) and with graphite oxide (GO) (black dashed curves), in neutral (squares) and acidic ( $\mathrm{pH}=1.3$; triangles) solutions.

\section{Conclusions}

An eco-friendly procedure leading to adducts of a cationic drug with charcoal, which is suitable for cationic drug release, is presented in this study. The proposed procedure includes oxidation by hydrogen peroxide in mild conditions of charcoal, which is widely commercialized for human ingestion without professional prescription.

The oxidation procedure is followed by preparation of oxidized charcoal adducts with lidocaine hydrochloride (a medication used as local anesthetic). For oxidized charcoal with an O/C weight ratio of 0.7 , a typical content of the drug in the prepared adducts is close to $30 \%$ by weight, nearly independent of the used excess of the drug.

Release behaviors of this cationic drug in neutral and acid aqueous solutions from lidocaine adducts with GO and oxidized charcoal are compared. The release of the ionic drug in the aqueous acid solution is complete after $1 \mathrm{~h}$. Both for neutral and acidic solutions the cation release is faster for the charcoal adduct than for the graphite oxide adduct.

The presently proposed cationic drug release system, with respect to other already known systems based on intercalation and exfoliation compounds of layered structures, has the advantage of being based on a solid substrate traditionally used for human ingestion, modified by a simple and eco-friendly procedure.

Author Contributions: Conceptualization M.R.A. and G.G.; investigation and data curation, C.D.R.; writing M.R.A.; supervision G.G.

Funding: This research received no external funding.

Acknowledgments: We thank Maurizio Galimberti of Politecnico of Milan and Pasquale Longo and Mario Maggio of University of Salerno for useful discussions. Financial support of "Ministero dell' Istruzione, dell' Università e della Ricerca" is gratefully acknowledged.

Conflicts of Interest: The authors declare no conflict of interest.

\section{References}

1. Severina, I.I.; Muntyan, M.S.; Lewis, K.; Skulachev, V.P. Transfer of cationic antibacterial agents berberine, palmatine, and benzalkonium through bimolecular planar phospholipid film and staphylococcus aureus membrane. IUBMB Life 2001, 52, 321-324. [CrossRef] [PubMed]

2. Savage, P.B.; Li, C.; Taotafa, U.; Ding, B.; Guan, Q. Antibacterial Properties of cationic steroid antibiotics. FEMS Microbiol. Lett. 2002, 217, 1-7. [CrossRef] [PubMed]

3. Strom, M.B.; Haug, B.E.; Skar, M.L.; Stensen, W.; Stiberg, T.; Svendsen, J.S. The Pharmacophore of short cationic antibacterial peptides. J. Med. Chem. 2003, 46, 1567-1570. [CrossRef] [PubMed] 
4. Zhang, L.Z.; Yu, J.C.; Yip, H.Y.; Li, Q.; Kwong, K.W.; Xu, W.; Wong, P.K. Ambient light reduction strategy to synthesize silver nanoparticles and silver-coated $\mathrm{TiO}_{2}$ with enhanced photocatalytic and bactericidal activities. Langmuir 2003, 19, 10372-10380. [CrossRef]

5. Ohashi, F.; Ueda, S.; Taguri, T.; Kawachi, S.; Abe, H. Antimicrobial activity and thermostability of silver 6-benzylaminopurine montmorillonite. Appl. Clay Sci. 2009, 46, 296-299. [CrossRef]

6. Findlay, B.; Zhanel, G.G.; Schweizer, F. Cationic amphiphiles, a new generation of antimicrobials inspired by the natural antimicrobial peptide scaffold. Antimicrob. Agents Chemother. 2010, 54, 4049-4058. [CrossRef] [PubMed]

7. Hoque, J.; Akkapeddi, P.; Yarlagadda, V.; Uppu, D.S.S.M.; Kumar, P.; Haldar, J. Cleavable cationic antibacterial amphiphiles: Synthesis, mechanism of action, and cytotoxicities. Langmuir 2012, 28, 12225-12234. [CrossRef] [PubMed]

8. van der Heyden, M.A.; Stary-Weinzinger, A.; Sanchez-Chapula, J.A. Inhibition of cardiac inward rectifier currents by cationic amphiphilic drugs. Curr. Mol. Med. 2013, 13, 1284-1298. [CrossRef]

9. Kuppusamy, R.; Yasir, M.; Berry, T.; Cranfield, G.C.; Nizalapur, S.; Yee, E.; Kimyon, O.; Taunk, A.; Ho, K.K.K.; Cornell, B.; et al. Design and synthesis of short amphiphilic cationic peptidomimetics based on biphenyl backbone as antibacterial agents. Eur. J. Med. Chem. 2018, 143, 1702-1722. [CrossRef] [PubMed]

10. Walvekar, P.; Gannimani, R.; Rambharose, S.; Mocktar, C.; Govender, T. Fatty acid conjugated pyridinium cationic amphiphiles as antibacterial agents and self-assembling nano carriers. Chem. Phys. Lipids 2018, 214, 1-10. [CrossRef] [PubMed]

11. Dailey, J.W. Pharmaceutical Industry; Encyclopædia Britannica, Inc.: Chicago, IL, USA, 2018.

12. Tan, J.P.K.; Goh, C.H.; Tam, K.C. Comparative drug release studies of two cationic drugs from pH-responsive nanogels. Eur. J. Pharm. Sci. 2007, 32, 340-348. [CrossRef] [PubMed]

13. Herrera, P.; Burghardt, R.C.; Phillips, T.D. Adsorption of salmonella enteritidis by cetylpyridinium-exchanged montmorillonite clays. Vet. Microbiol. 2000, 74, 259-272. [CrossRef]

14. Cai, X.; Tan, S.Z.; Liao, M.-H.; Wu, T.; Liu, R.F.; Yu, B. Thermal stability and long-acting antibacterial activity of phosphonium montmorillonites. J. Cent. South. Univ. Technol. 2010, 17, 485-491. [CrossRef]

15. Galimberti, M.; Giudice, S.; Cipolletti, V.; Guerra, G. Control of organoclay structure in hydrocarbon polymers. Polym. Adv. Technol. 2010, 21, 679-684. [CrossRef]

16. Cipolletti, V.; Galimberti, M.; Mauro, M.; Guerra, G. Organoclays with hexagonal rotator order for the paraffinic chains of the compensating cation. Implications on the structure of clay polymer nanocomposites. Appl. Clay Sci. 2014, 87, 179-188. [CrossRef]

17. Ramorino, G.; Bignotti, F.; Pandini, S.; Ricco, T. Mechanical reinforcement in naturalrubber/organoclay nanocomposites. Compos. Sci. Technol. 2009, 69, 1206-1211. [CrossRef]

18. Rhim, J.W.; Hong, S.I.; Ha, C.S. Tensile, water vapor barrier and antimicrobial properties of PLA/nanoclay composite films. LWT-Food Sci. Technol. 2009, 42, 612-617. [CrossRef]

19. Cai, X.; Tan, S.; Lin, M.; Xie, A.; Mai, W.; Zhang, X.; Lin, Z.; Wu, T.; Liu, Y. Synergistic antibacterial brilliant blue/reduced graphene oxide/quaternary phosphonium salt composite with excellent water solubility and specific targeting capability. Langmuir 2011, 27, 7828-7835. [CrossRef] [PubMed]

20. Xie, A.-G.; Cai, X.; Lin, M.-S.; Wu, T.; Zhang, X.-J.; Lin, Z.-D.; Tan, S. Long-acting antibacterial activity of quaternary phosphonium salts functionalized few-layered graphite. Mater. Sci. Eng. B 2011, 176, 1222-1226. [CrossRef]

21. Mauro, M.; Maggio, M.; Cipolletti, V.; Galimberti, M.; Longo, P.; Guerra, G. Graphite oxide intercalation compounds with rotator hexagonal order in the intercalated layers. Carbon 2013, 61, 395-403. [CrossRef]

22. Mauro, M.; Maggio, M.; Antonelli, A.; Acocella, M.R.; Guerra, G. Intercalation and exfoliation compounds of graphite oxide with quaternary phosphonium ions. Chem. Mater. 2015, 27, 1590-1596. [CrossRef]

23. Zhang, Y.; Yan, X.; Yan, Y.; Chen, D.; Huang, L.; Zhang, J.; Ke, Y.; Tan, S. The utilization of a three-dimensional reduced graphene oxide and montmorillonite composite aerogel as a multifunctional agent for wastewater treatment. RSC Adv. 2018, 8, 4239-4248. [CrossRef]

24. Maggio, M.; Acocella, M.R.; Guerra, G. Intercalation compounds of oxidized carbon black. RSC Adv. 2016, 6, 105565-105572. [CrossRef]

25. Park, I.S.; Park, M.O.; Hur, J.W.; Kim, D.S.; Chang, Y.J.; Kim, Y.J.; Park, J.Y.; Johnson, S.C. Anesthetic effects of lidocaine-hydrochloride on water parameters in simulated transport experiment of juvenile winter flounder, Pleuronectes americanus. Aquaculture 2009, 294, 76-79. [CrossRef] 
26. Meng, Q.-T.; Xia, Z.-Y.; Liu, J.; Bayliss, D.A.; Chen, X. Local anesthetic inhibits hyperpolarization-activated cationic currents. Mol. Pharm. 2011, 79, 866-873. [CrossRef]

27. Chen-Chow, P.-C.; Frank, S.G. In vitro release of lidocaine from pluronic F-127 gels. Int. J. Pharm. 1981, 8, 89-99. [CrossRef]

28. Chen, P.-C.; Kohane, D.S.; Park, Y.J.; Bartlett, R.H.; Langer, R.; Yang, V.C. Injectable microparticle-gel system for prolonged and localized lidocaine release.II.In vivo anesthetic effects. J. Biomed. Mater. Res. A 2004, 70, 459-466. [CrossRef]

29. Ricci, E.J.; Lunardi, L.O.; Nanclares, D.M.A.; Marchetti, J.M. Sustained release of lidocaine from Poloxamer 407 gels. Int. J. Pharm. 2005, 288, 235-244. [CrossRef] [PubMed]

30. Liu, D.-Z.; Sheu, M.-T.; Chen, C.-H.; Yang, Y.-R.; Ho, H.-O. Release characteristics of lidocaine from local implant of polyanionic and polycationic hydrogels. J. Control. Release 2007, 118, 333-339. [CrossRef]

31. Sawant, P.D.; Luu, D.; Ye, R.; Buchta, R. Drug release from hydroethanolic gels. Effect of drug's lipophilicity $(\log$ P), polymer-drug interactions and solvent lipophilicity. Int. J. Pharm. 2010, 396, 45-52. [CrossRef] [PubMed]

32. Mueller-Goymann, C.C.; Frank, S.G. Interaction of lidocaine and lidocaine hydrochloride with the liquid crystal structure of topical preparations. Int. J. Pharm. 1986, 29, 147-159. [CrossRef]

33. Perale, G.; Casalini, T.; Barri, V.; Mueller, M.; Maccagnan, S.; Masi, M.J. Lidocaine release from polycaprolactone threads. J. Appl. Polym. Sci. 2010, 117, 3610-3614. [CrossRef]

34. Vittore, A.; Acocella, M.R.; Guerra, G. Edge oxidation of graphite by hydrogen peroxide. Langmuir 2019, 35, 2244-2250. [CrossRef] [PubMed]

35. Hummers, S.W.R.; Offeman, E. Preparation of Graphitic Oxide. J. Am. Chem. Soc. 1958, 80, 1339. [CrossRef]

36. Mauro, M.; Cipolletti, V.; Galimberti, M.; Longo, P.; Guerra, G. Chemically reduced graphite oxide with improved shape anisotropy. J. Phys. Chem. C 2012, 116, 24809-24813. [CrossRef]

37. Nikafshar, S.; Zabihi, O.; Hamidi, S.; Moradi, Y.; Barzegar, S.; Ahmadi, M.; Naebe, M. A renewable bio-based epoxy resin with improved mechanical performance that can compete with DGEBA. RSC Adv. 2017, 7, 8694-8701. [CrossRef]

38. Canavate, J.; Colom, X.; Pages, P.; Carrasco, F. Study of the curing process of an epoxy resin by FTIR spectroscopy. Polym. Plast. Technol. Eng. 2000, 39, 937-943. [CrossRef] 